\title{
Coexistence of tooth agenesis and ovarian cancer - a systematic literature review
}

\author{
Weronika Gawron-Jakubek ${ }^{1}$, Kazimierz Pitynski ${ }^{2}$, Joanna Spaczynska² ${ }^{2}$ Bartlomiej W. Loster ${ }^{1}$ \\ ${ }^{1}$ Department of Orthodontics, Dental Institute, Faculty of Medicine, Jagiellonian University Medical College, Cracow, Poland \\ ${ }^{2}$ Department of Gynecology and Obstetrics, Faculty of Medicine, Jagiellonian University Medical College, Cracow, Poland
}

\begin{abstract}
Objectives: Dental agenesis - a congenital lack of teeth - is one of the most frequently diagnosed developmental defects of dentition. Genetics is a crucial factor in the etiology of this disorder. Missing teeth can be caused by mutation in genes including MSX1, PAX9, AXIN2, and EDARADD. As is also true for ovarian cancer, over $20 \%$ of cases are associated with hereditary factors. Mutations in the BRCA1 and BRCA2 genes are said to be the most frequent of these. The aim of this study was to provide a systematic review of the literature on the coexistence of ovarian cancer and tooth agenesis.

Material and methods: Publications were searched for in the online databases PubMed, SCOPUS, and Wiley Online Library. Current and archival issues of the Journal of Stomatology and Dental and Medical Problems were also searched. The key words used to find relevant publications were: ovarian cancer, hypodontia, and tooth agenesis, in various combinations.

Results: Three publications were qualified to this review. Two of these compared the incidence of hypodontia in women with ovarian cancer and in healthy women, and the other was aimed at locating the gene responsible for the coexistence of ovarian cancer and tooth agenesis. As shown by these studies, women with ovarian cancer are (depending on the study) 3.3 or 8.1 times more likely to have hypodontia than healthy women. However, no specific gene was found that might be responsible for the coexistence of ovarian cancer and tooth agenesis.
\end{abstract}

Key words: ovarian cancer; tooth agenesis; hypodontia

Ginekologia Polska 2019; 90, 12: 707-710

\section{INTRODUCTION}

Tooth agenesis is one of the most common anomalies of dental development in humans [1]. The congenital absence of one to six teeth is called hypodontia, while the absence of more than six is called oligodontia [2]. The incidence of hypodontia in the Caucasian population ranges from $0.027 \%$ to $10 \%$, and is slightly more common in women [3]. Both forms of congenital absence of teeth may occur in isolated form or as a component of congenital malformations. Studies have shown that hypodontia of permanent teeth - excluding agenesis of the third molars - most often concerns the lower second premolar, then the upper lateral incisor and upper second premolar $[3,4]$. These data coincide with the results of research conducted in the Orthodontic Jagiellonian University Dental Clinic, Cracow, where the prevalence of congenital absence of teeth in patients treated orthodontically in 1995-2003 and 2006-2007 was respectively $9.5 \%$ and $8.9 \%$; this was more common in women, and the most common missing tooth was the lower second pre- molar $[5,6]$. In the etiology of tooth agenesis, both genetic and environmental factors can be distinguished [7]. Three hundred genes take part in regulating the development of dentition [8]. The genes whose mutations have been described as a cause of agenesis include MSX1, PAX9, AXIN2, and EDARADD [9-21].

Ovarian cancer is the sixth most common malignant tumor in women in Poland and accounts for $5 \%$ of cases [22]. Morbidity increases with age, with $80 \%$ of cases diagnosed in people over 50 [22]. Five-year survival in the Polish population is around 50\% [22]. Unfortunately, there are no characteristic symptoms of cancer, which contributes to its late detection [22]. It is estimated that $22 \%$ of the risk of ovarian cancer is associated with hereditary factors [23]. The strongest known genetic risk factors for epithelial ovarian cancer are the BRCA1 and BRCA2 genes [24].

Emerging publications show a possible coincidence of ovarian cancer and tooth agenesis, which has induced us to write a systematic review of the literature in this area. 
The aim of the work is to present documented knowledge on this possible interdependence, obtained in a methodical manner from reliable sources of information. The dissemination of available information may help draw attention to this additional diagnostic aspect, which could be taken into account in oncological prevention and in the early detection of potential threats to women's general health.

\section{MATERIAL AND METHODS}

To gather as many relevant publications as possible, we searched the following internet databases covering articles in the field of medicine and biological sciences: PubMed, SCOPUS, and Wiley Online Library. The key words used to find relevant research were: ovarian cancer, hypodontia, and tooth agenesis, in various combinations. The search was restricted to full-text articles published in English or Polish. There was no restriction on year of publication. Current and archival issues of the Journal of Stomatology and Dental and Medical Problems were also searched.

All original publications regarding the relationship between ovarian cancer and tooth agenesis were approved for review. Literature reviews, editorial works, and letters to the editor have been excluded. If there was more than one article by the same author regarding the same study, only the first article was selected.

\section{RESULTS}

The result of the database search was a total of 850 items. After removal of 121 duplicates, 729 publications were available for the screening. According to the title and the abstract, 724 publications were removed because they were not related to the subject. Of the remaining 5 papers, 3 were included after applying the inclusion and exclusion criteria (Fig. 1) [25-27]. No additional publications were found in the dental journals listed above.

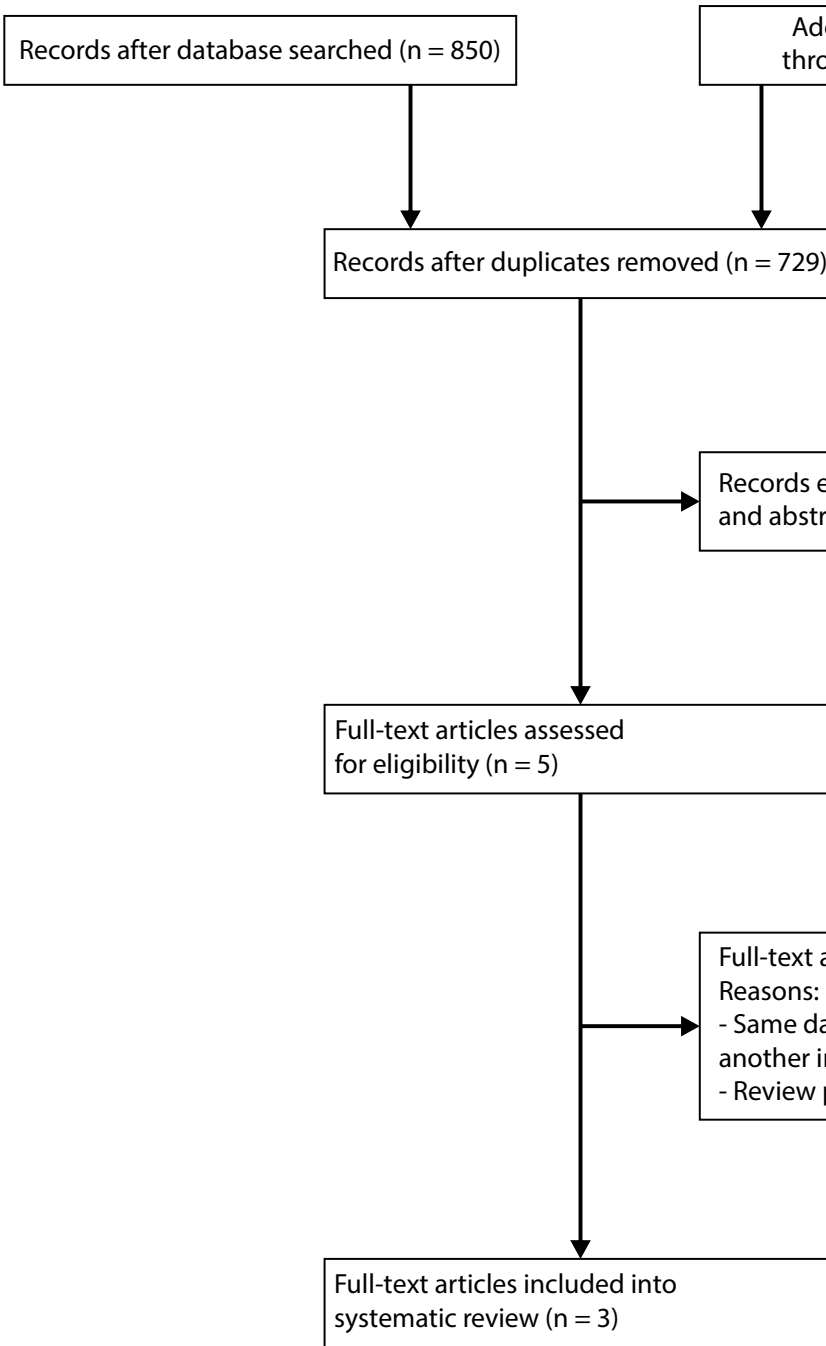

Figure 1. Flow chart of literature search and study selection 
Two of the publications aimed at comparing the frequency of hypodontia in women with EOC (epithelial ovarian cancer) and in healthy women, and the other attempted to locate the gene responsible for the coexistence of ovarian cancer and tooth agenesis [25-27]. All of the studies involved both women suffering from ovarian cancer and healthy women. The total number of examined patients was 485 , including 220 patients suffering from EOC, of whom 43 had hypodontia [25-27]. Only two studies used control groups, which contained 220 people in total $[25,26]$. Studies comparing the incidence of hypodontia in sick and healthy women showed that women with ovarian cancer are (depending on the study) 3.3 or 8.1 times more likely to have hypodontia $[25,26]$. It was also shown that, in patients with ovarian cancer, tooth agenesis occurs more often in the maxilla $[25,26]$. These publications do not agree on the tooth that is missing most often - both the upper lateral incisor and the upper second premolar are mentioned [26, 25]. Only one study took into account the division of hypodontia into unilateral and bilateral. Agenesis was much more frequent on one side of the study group [25]. In both studies, more than $20 \%$ of patients with hypodontia and ovarian cancer had a family history of congenital absence of teeth $[25,26]$. Genetic tests focused on mutations in the PAX9, EDA, WNT10A, MSX1, AXIN2, BARX1, BARX2, and BRCA1 genes [27]. One patient with coexisting ovarian cancer and tooth agenesis had mutations in the EDA and BRCA1 genes, another one only in the BRCA1 gene, and three in the WNT10A gene [27]. Unfortunately, the research of Bonds et al. did not indicate any specific gene that might be responsible for the coexistence of EOC and tooth agenesis [27]. This information is presented in Table 1.

\section{DISCUSSION}

The above data indicate more frequent occurrence of tooth agenesis in women with ovarian cancer than in healthy women. Despite these data, from 2014 to September 2018, no new research publications confirmed the hypothesis of the coincidence of hypodontia and ovarian cancer. In 2016, a review paper by lavazzo was published on the relationship between ovarian cancer and hypodontia; this qualified four publications for review [28], one of which was the publication of Fekonja et al. from 2015, which is a description of a study whose results were published a year earlier [27, 29], as can be seen from the location and year of the study, the size of the study and control group, and the frequency of hypodontia in both groups. This publication was therefore excluded from our review; it did, however, aim to compare data on the stage of advancement and the type of cancer in patients with and without hypodontia [29].

As mentioned earlier, genetic factors play a key role in the etiology of both ovarian cancer and tooth agenesis, and their co-occurrence may indicate overlapping genetic background. In a study conducted by Küchler et al., an increased risk of a family history of cancer was observed in patients with confirmed tooth agenesis [30]. Chalothorn et al. reported a family history of ovarian cancer in thirty percent of women with hypodontia and EOC, compared to zero percent in women with hypodontia without EOC [26]. Although the gene responsible for the coincidence of tooth agenesis and ovarian cancer has not yet been identified, it is worth emphasizing that studies show that the genes responsible for congenitally missing teeth may also contribute to the formation of cancer cells. Studies on a Finnish four-generation family showed that mutations within the AXIN2 gene simultaneously predispose to colon cancer and cause tooth agenesis [20]. This gene is also mentioned by Dimova et al. as a strong candidate for ovarian tumorigenesis [31]. Bonds et al. found mutations in the AXIN2 gene in one patient with ovarian cancer who did not have coexisting hypodontia [25]. Mutations within the PAX9 gene result in isolated oligodontia in the molars [10-15]. Gerber

\begin{tabular}{|l|l|l|l|}
\hline Table 1. Publications on the relationship between ovarian cancer and tooth agenesis \\
\hline & Fekonja et al. [25] & Chalothorn et al. [26] & Bonds et al. [27] \\
\hline Number of women in the study group & 120 & 50 & 95 \\
\hline Number of women in the control group & 120 & 100 & - \\
\hline Number of women with hypodontia and ovarian cancer & 23 & $10^{*}$ & 10 \\
\hline Number of women with hypodontia and without ovarian cancer & 8 & $3^{*}$ & - \\
\hline Odds ratio & $3.3(95 \% \mathrm{Cl}, 0.12-7.01)$ & 8.1 (95\% Cl, 2.1-30.9) & - \\
\hline Most often missing tooth ** & Upper second premolar & Upper lateral incisor & - \\
\hline Distribution of hypodontia ** & Unilaterally: 78.3\%; & - & - \\
\hline Family history of hypodontia ** & Bilaterally: 21.7\% & & - \\
\hline Family history of ovarian cancer ** & $21.7 \%$ & $60 \%$ & - \\
\hline Number of patients with a mutation in genes ** & - & $30 \%$ & - \\
\hline
\end{tabular}

* The criterion for inclusion in the group with hypodontia was tooth agenesis or microdontia

** in women with ovarian cancer and hypodontia 
et al. showed a correlation between the progressive loss of PAX9 gene expression and an increase in the malignancy of dysplastic and cancerous epithelium of the esophagus [32]. PAX9 gene expression has also been detected in ovarian cancer cell lines [33]. In contrast, the MSX1 gene is considered a potential repressor in cell proliferation and cell cycle progression in human ovarian cancer cells [34]. Mutations in the same gene are mentioned among the reasons for the occurrence of tooth agenesis $[17,18]$. So far, the relationship between the congenital absence of teeth and mutations in the BRCA 1 and BRCA2 genes - considered to be the best-known risk factors for ovarian cancer-has not been demonstrated.

\section{CONCLUSIONS}

Though studies point to the existence of a correlation between ovarian cancer and tooth agenesis, there is presently no conclusive evidence for their common genetic basis. Proving this hypothesis would identify tooth agenesis as a risk factor for ovarian cancer, and thus contribute to increased detection of this cancer in the early stages of the disease.

\section{REFERENCES}

1. Vastardis H. The genetics of human tooth agenesis: New discoveries for understanding dental anomalies. American Journal of Orthodontics and Dentofacial Orthopedics. 2000; 117(6): 650-656, doi: 10.1016/s08895406(00)70173-9.

2. Schalk van der Weide Y, Prahl-Andersen B, Bosman F. Tooth formation in patients with oligodontia. Angle Orthod. 1993; 63(1): 31-37, doi: 10.1043/0003-3219(1993)063<0031:TFIPWO>2.0.CO;2, indexed in Pubmed: 8507028.

3. Mattheeuws N. Has hypodontia increased in Caucasians during the 20th century? A meta-analysis. The European Journal of Orthodontics. 2004; 26(1): 99-103, doi: 10.1093/ejo/26.1.99.

4. Polder B, Hof MV, Linden FV, et al. A meta-analysis of the prevalence of dental agenesis of permanent teeth. Community Dentistry and Oral Epidemiology. 2004; 32(3): 217-226, doi: 10.1111/j.1600-0528.2004.00158.x.

5. Dyras M, Jankowska K, Czupryna S. Ocena częstotliwości występowania zaburzeń rozwojowych zębów u pacjentów leczonych w Katedrze Ortodoncji Instytutu Stomatologii Uniwersytetu Jagiellońskiego. Dent Med Probl. 2003; 40: 349-354.

6. Baczyk-Łopuch O, Hille A, Loster B. Estimation of hypodontia prevalence in patients treated at the Orthodontic Jagiellonian University Dental Clinic in Cracow. Journal of Stomatology (Czasopismo Stomatologiczne). 2014; 67(5): 624-636, doi: 10.5604/00114553.1127416.

7. Parkin N, Elcock C, Smith RN, et al. The aetiology of hypodontia:The prevalence, severity and location of hypodontia within families. Archives of Oral Biology. 2009; 54: S52-S56, doi: 10.1016/j.archoralbio.2008.11.002.

8. Thesleff I. The genetic basis of tooth development and dental defects. American Journal of Medical Genetics Part A. 2006; 140A(23): 2530-2535, doi: 10.1002/ajmg.a.31360.

9. Bergendal B, Klar J, Stecksén-Blicks C, et al. Isolated oligodontia associated with mutations in EDARADD, AXIN2, MSX1, and PAX9 genes. American Journal of Medical Genetics Part A. 2011; 155(7): 1616-1622, doi: 10.1002/ajmg.a.34045.

10. Frazier-Bowers SA, Guo DC, Cavender A, et al. A Novel Mutation in HumanPAX9Causes Molar Oligodontia. Journal of Dental Research. 2017; 81(2): 129-133, doi: 10.1177/0810129.

11. Jumlongras $D$, Lin JY, Chapra A, et al. A novel missense mutation in the paired domain of PAX9 causes non-syndromic oligodontia. Human Genetics. 2004; 114(3): 242-249, doi: 10.1007/s00439-003-1066-6.

12. Klein ML, Nieminen $P$, Lammi L, et al. Novel Mutation of the Initiation Codon of PAX9 Causes Oligodontia. Journal of Dental Research. 2016; 84(1): 43-47, doi: 10.1177/154405910508400107.
13. Mostowska A, Kobielak A, Biedziak B, et al. Novel mutation in the paired box sequence of PAX9 gene in a sporadic form of oligodontia. European Journal of Oral Sciences. 2003; 111(3): 272-276, doi: 10.1034/j.16 00-0722.2003.00036.x

14. Mostowska A, Biedziak B, Trzeciak W. A novel mutation in PAX9 causes familial form of molar oligodontia. European Journal of Human Genetics. 2005; 14(2): 173-179, doi: 10.1038/sj.ejhg.5201536.

15. Nieminen $P$, Arte $S$, Tanner $D$, et al. Identification of a nonsense mutation in the PAX9 gene in molar oligodontia. European Journal of Human Genetics. 2001; 9(10): 743-746, doi: 10.1038/sj.ejhg.5200715.

16. Vastardis H, Karimbux N, Guthua S, et al. A human MSX1 homeodomain missense mutation causes selective tooth agenesis. Nature Genetics. 1996; 13(4): 417-421, doi: 10.1038/ng0896-417.

17. Boogaard MJv, Dorland M, Beemer F, et al. MSX1 mutation is associated with orofacial clefting and tooth agenesis in humans. Nature Genetics. 2000; 24(4): 342-343, doi: 10.1038/74155.

18. Lidral AC, Reising BC. The Role of MSX1 in Human Tooth Agenesis. Journal of Dental Research. 2016; 81(4): 274-278, doi: 10.1177/154405910208100410.

19. Ogawa T, Kapadia H, Feng J, et al. Functional Consequences of Interactions betweenPax9andMsx1Genes in Normal and Abnormal Tooth Development. Journal of Biological Chemistry. 2006; 281 (27): 18363-18369, doi: 10.1074/jbc.m601543200.

20. Lammi L, Arte S, Somer M, et al. Mutations in AXIN2 Cause Familial Tooth Agenesis and Predispose to Colorectal Cancer. The American Journal of Human Genetics. 2004; 74(5): 1043-1050, doi: 10.1086/386293.

21. Mostowska A, Biedziak B, Jagodzinski PP. Axis inhibition protein 2 (AXIN2) polymorphisms may be a risk factor for selective tooth agenesis. J Hum Genet. 2006; 51(3): 262-266, doi: 10.1007/s10038-005-0353-6, indexed in Pubmed: 16432638.

22. Krajowy Rejestr Nowotworów. http://onkologia.org.pl (accessed: 30.09.2018).

23. Lichtenstein $\mathrm{P}, \mathrm{Holm} \mathrm{N}$, Verkasalo $\mathrm{P}$, et al. Environmental and Heritable Factors in the Causation of Cancer - Analyses of Cohorts of Twins from Sweden, Denmark, and Finland. New England Journal of Medicine. 2000; 343(2): 78-85, doi: 10.1056/nejm200007133430201.

24. Bolton KL, Ganda C, Berchuck A, et al. Role of common genetic variants in ovarian cancer susceptibility and outcome: progress to date from the ovarian cancer association consortium (OCAC). Journal of Internal Medicine. 2012; 271(4): 366-378, doi: 10.1111/j.1365-2796. 2011.02509.x.

25. Fekonja A, Čretnik A, Takač I. Hypodontia prevalence and pattern in women with epithelial ovarian cancer. The Angle Orthodontist. 2014; 84(5): 810-814, doi: 10.2319/112813-876.1.

26. Fekonja A, Cretnik A, Zerdoner D, et al. Hypodontia phenotype in patients with epithelial ovarian cancer. Radiology and Oncology. 2015; 49(1): 65-70, doi: 10.2478/raon-2014-0034.

27. Bonds J, Pollan-White $S$, Xiang $\mathrm{L}$, et al. Is there a link between ovarian cancer and tooth agenesis? European Journal of Medical Genetics. 2014; 57(5): 235-239, doi: 10.1016/j.ejmg.2014.02.013.

28. lavazzo C, Papakiritsis M, Gkegkes ID. Hypodontia and ovarian cancer: A systematic review. Journal of the Turkish German Gynecological Association. 2016; 17(1): 41-44, doi: 10.5152/jtgga.2015.15174.

29. Fekonja A, Cretnik A, Zerdoner D, et al. Hypodontia phenotype in patients with epithelial ovarian cancer. Radiology and Oncology. 2015; 49(1): 65-70, doi: 10.2478/raon-2014-0034.

30. Küchler EC, Lips A, Tannure PN, et al. Tooth Agenesis Association with Self-reported Family History of Cancer. Journal of Dental Research. 2012; 92(2): 149-155, doi: 10.1177/0022034512468750.

31. Dimova I, Orsetti B, Negre V, et al. Genomic Markers for Ovarian Cancer at Chromosomes 1, 8 and 17 Revealed by Array CGH Analysis. Tumori Journal. 2018; 95(3): 357-366, doi: $10.1177 / 030089160909500315$.

32. Gerber JK, Richter T, Kremmer E, et al. Progressive loss of PAX9 expression correlates with increasing malignancy of dysplastic and cancerous epithelium of the human oesophagus. The Journal of Pathology. 2002; 197(3): 293-297, doi: 10.1002/path.1115.

33. Muratovska A, Zhou C, He S, et al. Paired-Box genes are frequently expressed in cancer and often required for cancer cell survival. Oncogene. 2003; 22(39): 7989-7997, doi: 10.1038/sj.onc.1206766.

34. Park J, Park K, Kim S, et al. Msx 1 Gene Overexpression Induces G1 Phase Cell Arrest in Human Ovarian Cancer Cell Line OVCAR3. Biochemical and Biophysical Research Communications. 2001; 281(5): 1234-1240, doi: 10.1006/bbrc.2001.4474. 